63 InterAção

\title{
VIGIAS E VIGIADOS: VARIÁVEIS E ELEMENTOS PARA PESQUISA COMPARATIVA SOBRE A MIGRAÇÃO NA FRONTEIRA BRASIL-FRANÇA
}

\author{
Daniel Santiago Chaves ${ }^{1}$
}

Whitney Cabral ${ }^{2}$

\section{Resumo}

Este trabalho pretende ensejar possibilidades e notas para uma pesquisa comparativa analisando os níveis de cooperação envolvendo Brasil e França no que diz respeito a temas de cimeira, como os recorrentes problemas de cooperação, com foco no que as suas políticas externas - e a decorrente variedade de ações, legislações e atos implicam - apontam sobre o comportamento dos dois Estados diante do assunto de grande prioridade para a fronteira guiano-amapaense e para o debate global e regional. Inevitavelmente, serão observados aspectos sobre o estado-da-arte na cooperação em política externa, mais especificamente sobre como pode-se apontar conceitos e abordagens basilares para temas ligados à imigração.

Palavras-chave: cooperação; políticas externas; fronteira; migrações internacionais.

\begin{abstract}
This paper intends to provide possibilities and notes for a comparative research analyzing the levels of cooperation involving Brazil and France regarding summit themes, such as the recurring problems of cooperation, focusing on what their foreign policies - and the resulting variety of actions, legislation and acts imply - point to the behavior of both States on the topic of high priority for the French Guiana-Amapa border and for the global and regional debate. Inevitably, aspects of state of art in
\end{abstract}

\footnotetext{
${ }^{1}$ Doutor em História Comparada pela Universidade Federal do Rio de Janeiro (PPGHC/UFRJ). Professor adjunto de História Contemporânea na Universidade Federal do Amapá (Unifap), docente permanente do Programa de PósGraduação em Mestrado em Desenvolvimento Regional (PPGMDR/Unifap), do Programa de Pós-Graduação em Estudos de Fronteira (PPGEF/Unifap) e do Pólo Unifap do Mestrado Profissional em Ensino de História (ProfHistória/CAPES). Pesquisador sênior do Observatório de Fronteiras do Platô das Guianas (OBFRON) e do Círculo de Pesquisas do Tempo Presente (CPTP), ambos da Unifap.

2 Graduada em Relações Internacionais pela Universidade Católica de Brasília (UCB). Mestranda em Estudos de Fronteira pela Universidade Federal do Amapá (PPGEF/Unifap). Pesquisadora do Círculo de Pesquisas do Tempo Presente (CPTP/Unifap).
} 
$64 \mid$ InterAção

foreign policy cooperation will be observed, more specifically on how concepts and basilar approaches to immigration issues can be pointed out.

Keywords: cooperation; foreign policies; border; international migrations.

\section{INTRODUÇÃO}

Deduz-se que a época contemporânea é integrada por redes que interligam a humanidade de um polo a outro em diversos setores (HELD; MCGREW, 2003). Temas relacionados a política, economia, cultura, sociedade, estão entrelaçados entre si de maneira firme e espessa num mundo regido pela tecnologia digital. Nesse contexto, distâncias foram reduzidas e o rápido acesso à informação criou um cenário moderno e comunicativo. Entretanto, a mesma teia que interconecta o mundo na atualidade, não foi capaz de dissipar os fluxos mais antigos, nem as razões de sua existência. Um claro exemplo dessa conjuntura se apresenta na situação das migrações internacionais.

Segundo Martine (2005), para se compreender o assunto em questão é necessário perceber a expansão da visão do migrante, a qual não mais se limita apenas à cidade mais próxima. Para o autor, a globalização rejeita fronteiras geográficas, modifica paradigmas e esbanja luxos e informações, que estimulam o consumo e os sonhos dos cidadãos. Estes criam expectativas de uma vida melhor e a buscam por meio da mudança de ambiente.

Pinto (2008), por sua vez, observa que entre os que anseiam por mais oportunidades também estão refugiados e vítimas de conflitos internos. Distribuída pelo mundo inteiro, a camada populacional composta pelos migrantes vê na transladação a saída para seus problemas. Dessa forma, imbróglios referentes a desemprego, conflitos, entre outras situações sociais 
65 | InterAção

adversas, motivam grupos cada vez maiores a deixarem seu país de origem. Dados de 2015, recolhidos pelo Alto Comissariado das Nações Unidas para Refugiados (ACNUR), indicam que mais de 65 (sessenta e cinco) milhões de pessoas são vítimas do deslocamento forçado nos dias de hoje.

Todavia, mesmo que a globalização figure como peça importante na discussão sobre fluxos migratórios, é essencial avaliar outro fator de grande relevância nessa análise: o papel do Estado. Como pondera Teitelbaum (2002), é comum encontrar pesquisas sobre migrações internacionais que se referem às mesmas como um "fluxo global", resultante de uma série de forças econômicas, sociais e políticas. Tais estímulos seriam tão potentes, que os governos pouco poderiam fazer sobre o assunto, além de sair do caminho.

O mesmo autor assevera, porém, que todos os Estados realizam intervenções dessa natureza, com maior ou menor eficácia, de maneira implícita ou explícita, e influenciam tanto no volume quanto na composição dos movimentos internacionais. Isto é, enquanto alguns países tentariam criar meios para afetar o potencial de migrações, a maioria das ações estaria voltada a atingir os níveis reais de migração, independentemente de seu potencial. Por meio da criação de políticas estatais, esses deslocamentos seriam estimulados e/ou restringidos (TEITELBAUM, 2002). O Brasil, como signatário dos principais tratados das Nações Unidas sobre os direitos humanos, também possui uma lei (Lei de Refúgio, No. 9.474/97) e um órgão interministerial (Comitê Nacional para os Refugiados - CONARE) específicos para o resguarde a refugiados. Segundo estatísticas do referido organismo, atualmente 8.863 (oito mil, oitocentos e sessenta e três) refugiados reconhecidos, de 79 nacionalidades diferentes residem em território brasileiro. Dentro deste total, 25\% (vinte e cinco por cento) estão somente na região norte, a qual ocupa o terceiro lugar no ranking de domicílios desse grupo no país (ACNUR, 2016). 
66 | InterAção

No entanto, cabe destacar uma peculiaridade quanto ao processo migratório no plano brasileiro. Enquanto muitos povos veem o Brasil como o local que lhes dará liberdade, paz e maiores chances de crescimento, os cidadãos locais se sentem insatisfeitos com as condições do país e desejam deixá-lo. Os motivos são variados e vão desde a busca por melhores oportunidades de trabalho ao desejo de ascensão social em países mais desenvolvidos.

De acordo com informações obtidas em 2016 pelo Instituto Brasileiro de Geografia e Estatística (IBGE) e pelo Ministério das Relações Exteriores (MRE), calcula-se que a comunidade brasileira no exterior já seja de 3.083 .255 (três milhões, oitenta três mil, duzentos e cinquenta e cinco) pessoas. Vale ressaltar que tais dados dizem respeito apenas ao total de imigrantes legais, já que a contagem dos que se encontram em situação ilegal é complexa. Segundo Pinto (2008, p. 18),

(...) o desejo, mesmo de modo clandestino de se chegar aos Estados Unidos pelo México ou chegar a Guiana Francesa pelo Oiapoque, para milhões de trabalhadores imigrantes parece ser o mesmo, ou seja: conseguir trabalho e viabilizar melhores condições de vida.

Segundo Baldwin (2010), os movimentos migratórios já ocorriam em escala regional, dentro do Brasil. Estes tinham como destino regiões mais desenvolvidas do país - em especial o Sudeste. Porém, quando tais locais começaram a demonstrar certo "inchaço" populacional, bem como redução de oportunidades, o desejo dos cidadãos por melhores condições de vida tomou outros rumos. Logo, os brasileiros ultrapassaram fronteiras geográficas, idiomáticas e alcançaram outros países e formaram, ao longo dos anos, uma vasta comunidade que cresce até os dias de hoje. 
67 InterAção

Quanto à Guiana Francesa, em especial, pondera-se que a primeira leva de migrantes tenha chegado ao território durante a segunda metade do século XX. Segundo Baldwin (2010), foi o período de construção da base espacial francesa na localidade de Kourou - quando, devido à baixa densidade populacional, o departamento ultra-marino precisou de mão-de-obra estrangeira. $O$ contingente que chegou ao lado francês nessa época, adentrou o território por meios legais, com contratos de trabalho. A instabilidade na emigração brasileira para aquele local ocorreu posteriormente, pois os salários e as condições de vida oferecidas eram bastante atrativos, o que impulsionou deslocamentos clandestinos (BALDWIN, 2010).

O número de brasileiros presentes no referido território, bem como os que intentam atravessar a fronteira, sofreu considerável aumento ao longo das décadas. De acordo com dados do Consulado-Geral do Brasil em Caiena (2016), a Guiana Francesa tem aproximadamente 278.511 (duzentos e setenta e oito mil, quinhentos e onze) habitantes, dos quais se estima que 40.550 (quarenta mil, quinhentos e cinquenta) sejam brasileiros (MRE, 2016). Por estar localizada numa região geograficamente difícil para manter uma fiscalização adequada, a costa guianense é constantemente invadida por imigrantes ilegais.

No lado brasileiro, aparentemente não há também uma política eficiente para regular a saída de cidadãos rumo ao território estrangeiro. A expectativa de uma ação conjunta entre os dois Estados - Brasil e França - surgiu com o estabelecimento das primeiras negociações para a construção da ponte binacional na fronteira. Esse empreendimento traria avanços nas relações bilaterais franco-brasileiras em diversos setores - comercial, turístico, político, cultural, entre outros. Hoje, cinco anos após o término da obra, a referida ponte ainda não somente segue fechada para trânsito, quanto os diálogos a respeito de sua inauguração ainda são tímidos (G1, 2017). 
68 InterAção

Dessa maneira, o estudo do tema em questão se faz essencial, para compreender não somente como a dinâmica das migrações ocorre, mas para identificar quais medidas de cooperação desenvolver as relações, definindo comportamentos e nivelando a cooperação em seus níveis.

\section{OPÇÕES CONCEITUAIS E PREMISSAS TEÓRICAS}

Pode-se ponderar acerca da colocação dos autores mobilizados que, muitas vezes os migrantes não buscam somente países distantes ou até mesmo extracontinentais. A região norte do Brasil que, como dito anteriormente, abriga um dos maiores índices de refugiados no país, também tem "exportado" habitantes aos territórios vizinhos. A Guiana Francesa, departamento ultramarino francês na América do Sul, é um desses destinos. A compreensão desse fenômeno sob o ponto de vista das ações estatais é o objeto de estudo desta pesquisa, com a seguinte pergunta norteadora: Como se dá a interferência do Estado, enquanto agente regulador, nas migrações de brasileiros para a Guiana Francesa?

No caso da parte brasileira, pouca atenção é concedida em prol da formulação de políticas que fiscalizem e controlem as migrações. Na Guiana Francesa, há dificuldade em manter uma fiscalização eficiente na fronteira por conta da floresta densa. Para tanto, a hipótese a ser trabalhada na presente pesquisa é a de falha conjunta na ação do Estado como agente regulador, tanto do lado brasileiro, quanto do lado francês.

O aumento significativo nos processos migratórios desperta a necessidade de analisar esse tema com maior profundidade. Especificamente sobre as migrações para a Guiana Francesa, é essencial estabelecer um 
69 | InterAção

entendimento sobre temas basilares para a referida análise. Portanto, os aspectos que norteiam o início do referido estudo, para dialogar com o histórico e a evolução do problema apresentado, são: globalização e migrações internacionais (conceitos e teorias), segurança regional e cooperação internacional.

Segundo Modelski (in: HELD; MCGREW, 2003), a globalização trata da história recente do envolvimento entre as principais civilizações existentes no mundo, cuja interpretação deve ser vista como um processo histórico longo que se estende até os primeiros encontros casuais entre as sociedades. Contudo, para Held e McGrew (2003), a ascensão e expansão do Ocidente juntamente com a modernidade, foram fatores decisivos no talho da globalização. O desenrolar do terceiro milênio, é marcado pela evolução das comunicações e dos novos fluxos: é a era da tecnologia da informação. No mundo digital, as civilizações se veem interconectadas por uma série de teias duradouras que as engajam em diversos níveis: econômico, político, cultural, social, informacional, entre outros. Para Modelski, globalização é

um conceito que captura esse processo histórico de ampliação e aprofundamento de interdependências sistêmicas entre nações, civilizações e comunidades políticas. É um processo que passou a definir a condição contemporânea e que em última instância levanta questões políticas profundas sobre se prefigura o surgimento de uma sociedade mundial ou de uma comunidade global. (in: HELD; MCGREW, 2003, p. 51) ${ }^{3}$

Para a análise desse fenômeno, três teorias serão apresentadas a seguir: a hiperglobalista, a cética e a transformacionalista. Os hiperglobalistas acreditam na globalização como um fenômeno novo e real, no qual o Estado é enfraquecido em detrimento das instituições transnacionais. Já os adeptos da

\footnotetext{
${ }^{3}$ is a concept which captures this historical process of the widening and deepening of systemic interdependencies amongst nations, civilizations and political communities. It is a process which has come to define the contemporary condition and one which ultimately raises profound political questions as to whether it prefigures the emergence of a world society or global community. (HELD; MCGREW, 2003, p. 51)
} 
70 | InterAção

tese cética, veem a globalização como mito, pois não teriam acontecido mudanças significativas nas relações entre os países, além das ocorridas em processos de regionalização e internacionalização. Por fim, a abordagem transformacionalista defende a formação de uma nova ordem mundial, definida a partir da força transformadora da globalização, a qual entrelaça assuntos internacionais e domésticos (relações "intermésticas") e mexe com economias, instituições de governança e estruturas da sociedade (HELD; MCGREW, 1999).

No que diz respeito aos fluxos migratórios no eixo Brasil-Guiana Francesa, a lente transformacionalista é a que melhor traduz a complexidade e peculiaridade da situação estabelecida nessa fronteira amazônica. $O$ departamento francês localizado na América do Sul é o primeiro exemplo disso. A distância geopolítica entre Brasil e o continente europeu é reduzida com a existência de uma fronteira franco-brasileira física. O próprio perfil guianense figura como outro exemplo da flexibilidade descrita pela teoria transformacionalista. Segundo Silva e Rückert (2008), o retrato é singular: um território geograficamente sul-americano, arraigado à Europa e seus modelos quanto à política e à economia, mas com uma cultura historicamente vinculada às ilhas caribenhas. Além disso, relatos sobre cidadãos que se dividem entre a moradia fixa em cidades brasileiras e o trabalho em municípios do departamento ultramarino francês são comuns (PINTO, 2008), o que possibilita até mesmo questionar a existência da fronteira na forma como foi estabelecida convencionalmente.

Segundo definição dada pelo Departamento de Relações Econômicas e Sociais das Nações Unidas (2013), a migração internacional é um fenômeno global. Em vista disso, é tanto causa quanto efeito de amplos processos de desenvolvimento, além de ser marca intrínseca de um mundo em constante globalização. 
71 | InterAção

Não obstante, como dito anteriormente, a globalização não é a única peça chave para a compreensão das migrações internacionais. A intervenção do Estado, além de real, é essencial. De acordo com Teitelbaum (2002), as políticas de interferência dividem a ação dos Estados entre categorias distintas. Dentre as mesmas, para fins de análise do tema proposto, podem destacadas as seguintes (a serem explanadas abaixo): exportadores de migrantes, promotores de imigração e reguladores de entrada.

1. Exportadores de migrantes: Estados que formulam políticas públicas explícitas ou implícitas (por meio de acordos e/ou tratados) para facilitar a saída de cidadãos de seu próprio território para viverem em outros países;

2. Promotores de imigração: Estados que detectaram baixa densidade demográfica em seu território e/ou necessitam de mão-de-obra para tarefas ou profissões específicas. Esses países decidem contratar estrangeiros para desempenhar tais funções;

3. Reguladores de Entrada: quase todos os Estados adotam medidas de regulação na entrada de migrantes, que vão desde o controle policial em fronteiras a sanções aplicadas a estrangeiros que não cumprem as regras estabelecidas. As únicas exceções, nas quais os países abrem mão desse direito, dizem respeito a acordos internacionais (como o que proíbe a recusa a refugiados vítimas de perseguição), e acordos bilaterais ou multilaterais (como é o caso da União Europeia).

Na relação entre Brasil e França, pode-se inferir que no início das migrações brasileiras, para a construção da base espacial de Kourou, o lado francês adotou um posicionamento voltado à promoção da imigração. Isto ocorreu porque, diante da baixa densidade demográfica e da necessidade de mão-de-obra para trabalhar em seu território, aquele flanco contratou um 
72 | InterAção

amplo contingente de estrangeiros, incluindo brasileiros (BALDWIN, 2010). Entretanto, com o avanço das migrações em massa - inclusive de forma clandestina -, a regulação da entrada no referido departamento foi reforçada. Quanto às ações adotadas pelo lado brasileiro, não é certo afirmar que o mesmo assumiu uma posição de exportador de migrantes, pois não foram encontradas evidências de políticas criadas para facilitar a saída de cidadãos brasileiros para o território francês. Mas, também foi detectada uma certa falha na elaboração de políticas para o controle de emigração para a Guiana Francesa, já que as mesmas seguem aumentando em número ao longo das décadas. Diante dessas inferências iniciais, cabe investigar quais as ameaças detectadas pelos dois lados, brasileiro e francês, na atualidade, além das políticas e ações foram, de fato, elaboradas especificamente para a questão das migrações na região.

Segundo Buzan e Wæver (2003), ao se refletir a respeito desse conceito, leva-se em consideração dois níveis, nacional e global. $O$ primeiro não proporciona uma análise tão significativa, pois a própria ideia de segurança necessita de uma potencial ameaça - somente possível num contexto relacional. A segunda, por sua vez, refere-se mais a uma aspiração do que à realidade, pois o mundo não está tão interconectado em termos de segurança, ao ponto de este tipo de reflexão retratar os anseios da maioria dos países (BUZAN; WæVER, 2003).

Para os autores supramencionados, em contrapartida, a segurança regional é uma realidade mais palpável. Isto ocorre porque a mesma faz referência a um nível de interação no qual Estados ou outras unidades possuem conexões tão próximas, que suas seguranças não podem mais ser consideradas separadas uma da outra (BUZAN; WÆVER, 2003). Desse modo, é comum as regiões fronteiriças serem vistas com incerteza quando se trata de fluxos migratórios. 
73 | InterAção

\section{APONTAMENTOS SOBRE SOBERANIA E COOPERAÇÃO NA FRONTEIRA FRANCO-BRASILEIRA}

Na Amazônia Setentrional a manutenção da segurança regional é bastante complexa. Isto acontece devido ao baixo nível de desenvolvimento regional, baixa densidade populacional, além da forte dependência dos grandes centros políticos e econômicos dos países que abrangem a região. A situação da dependência política e econômica exemplificada descreve o próprio cenário da Guiana Francesa. Elevado a departamento ultra-marino francês, o referido território possui um perfil extremamente distinto da França europeia. Apesar de compartilhar de semelhanças, as autoridades presentes nessa região não estão autorizadas a tomar decisões em relação a temas que alcançam a magnitude da segurança regional, por exemplo. Tal realidade ocasiona isolamento em relação aos países vizinhos e dependência da França metropolitana. Esta última é que retém a competência sobre as decisões a serem tomadas, as quais podem ser executadas de maneira inadequada (SILVA; RÜCKERT, 2008).

Outra preocupação crucial quando se trata de Amazônia diz respeito à defesa. Isso se dá, entre outras razões, pela importância da região enquanto ponto estratégico, onde se concentram uma gama de recursos naturais. Registros da imprensa mostram, inclusive, como esses fatores afetam as migrações. Na Guiana Francesa, as autoridades presentes na fronteira estão cada vez mais criteriosas, para garantir que imigrantes ilegais não adentrem o território. Relatos fornecidos por jornais, mostram como a exploração ao departamento ultra-marino em questão é antiga. Há informações de que um grupo de garimpeiros, entre eles 140 (cento e quarenta) brasileiros, teria invadido o lado francês em 1991 (AROUCK, 2000). Assim, um dos principais argumentos que embasam a severidade da polícia francesa, é justamente a crença de que essas pessoas estariam apenas tentando explorar os recursos 
74 | InterAção

naturais disponíveis naquele lado (SBT, 2013). Proteger uma região tão densa não é tarefa fácil - e historicamente a solução encontrada no lado brasileiro conta com o auxílio das Forças Armadas. Estas veem nos problemas de fronteira, bem como na conservação da soberania nacional na região, assuntos de grande relevância em seu planejamento estratégico. Não menos importante, é preciso problematizar o aspecto para além de uma questão de Defesa, ampliando o leque de compreensão sobre a noção de Segurança e inclui-la em um plano cooperativo e multilateral.

O conceito de cooperação internacional, segundo Keohane (1984), está diretamente ligado ao trânsito complexo entre harmonia e discórdia no qual os atores interagem no sistema internacional. Numa situação de harmonia, as políticas formuladas para os interesses de um determinado Estado convergem em prol de outro automaticamente, sem que ambos necessitem acordar qualquer ação. Já a discórdia, segundo o mesmo autor, ocorre quando os Estados encontram dificuldades em ajustar políticas e interesses entre si, entrando em desacordo. Nesse ponto, a cooperação, isto é, a coordenação de políticas conjuntas em prol de determinado fim, se faz essencial. O contexto das migrações internacionais na linde Amapá-Guiana Francesa é um bom exemplo para aplicação do conceito supramencionado. As controvérsias detectadas necessitam de medidas por parte dos dois Estados, para minimizar a iminência de conflitos e criar um ambiente harmônico, do ponto de vista da cooperação. Vale ressaltar, entretanto, que os governos se utilizam de meios para regular o contingente e os atributos dos estrangeiros que entram, residem em seu território, bem como as vias pelas quais se naturalizam (GEST et al., 2014). A partir da obtenção dessas informações é possível estabelecer uma lógica comparativa entre fatos e padrões de ação que possibilitam compreender, além de mensurar transformações, perceber regularidades, semelhanças e distinções que superam a mera observação dos fenômenos sociais (SCHNEIDER; 
75 | InterAção

SCHIMITT, 1998). No presente trabalho conclui-se, portanto, que se devem mensurar as medidas de cooperação internacional entre Brasil e França para as migrações internacionais, com vistas a analisar seus níveis de maneira comparativa seus padrões de comportamento.

\section{REFERÊNCIAS}

ACNUR. Dados sobre refúgio no Brasil. Balanço até abril de 2016. Disponível em: <http://www.acnur.org/portugues/recursos/estatisticas/dados-sobrerefugio-no-brasil/> Acesso em: 10 jan. 2017

Estatísticas. Tendências Globais sobre refugiados e outras populações de interesse do ACNUR. Disponvel em:

<http:// www.acnur.org/portugues/recursos/estatisticas/> Acesso em: 10 jan. 2017

AROUCK, Ronaldo. Brasileiros na Guiana francesa: Novas migrações internacionais ou exportação de tensões sociais na Amazônia? Lusotopie. Paris, p. 67-78, 2000. Disponível em:

<http://www.lusotopie.sciencespobordeaux.fr/arouck.pdf> Acesso em: 07 jan. 2017

BALDWIN, Elisabeth. Olhares cruzados sobre a imigração brasileira para a guiana francesa: novas representações identitárias? Synergies. Brasil, $\mathrm{n}^{\circ}$. spécial 1, p. 209-222, 2002. Disponível em:

<http://gerflint.fr/Base/BresilSPECIAL1/elisabeth_baldwin.pdf> Acesso em: 09 jan. 2017

BUZAN, Barry; WÆVER, Ole. Regions and Powers: The Structure of International Security. 1 $^{\text {st }}$ Ed., Cambridge: Cambridge University Press, 2003.

GEST, Justin, et al. Measuring and Comparing Immigration, Asylum and Naturalization Policies Across Countries: Challenges and Solutions. Global Policy. Durham, p. 1-14, 2014. Disponível em:

<https://www.researchgate.net/profile/Anna_Boucher/publication/27708884 6_Comparing_Immigration_Policies_An_Overview_from_the_IMPALA_Datab ase/links/55c3e8d408aeca747d5fb162.pdf> Acesso em: 16 jan. 2017

HELD, David; MCGREW, Anthony G. The Global Transformations Reader: an introduction to the globalization debate. $2^{\text {nd }}$ Ed., Cambridge: Polity, 2003. 
76 | InterAção

HELD, David; MCGREW, Anthony G.; GOLDBLATT, David; PERRATON, Jonathan. Global transformations: Politics, Economics and Culture. $1^{\text {st }}$ Ed., Stanford: Stanford University Press, 1999.

KEOHANE, Robert O. After hegemony: Cooperation and Discord in the World Political Economy. $1^{\text {st }}$ Ed., Princeton: Princeton University Press, 1984.

MARTINE, George. A globalização inacabada: migrações internacionais e pobreza no século 21. São Paulo em Perspectiva. São Paulo, v. 19, n. 3, p. 3-22, jul./set. 2005. Disponível em:

<http://www.scielo.br/pdf/spp/v19n3/v19n3a01.pdf> Acesso em: 07 jan. 2017

MINISTÉRIO DAS RELAÇÕES EXTERIORES. Brasileiros no mundo.

Estimativas populacionais das comunidades. Disponível em:

<http:/ / www.brasileirosnomundo.itamaraty.gov.br/a-

comunidade/estimativas-populacionais-das-

comunidades/Estimativas\%20RCN\%202015\%20-\%20Atualizado.pdf> Acesso em: 10 jan. 2017

Consulado-Geral do Brasil em Caiena. Disponível em:

<http:/ / caiena.itamaraty.gov.br/pt-br/guiana_francesa___informacoes.xml> Acesso em 14 jan. 2017

MODELSKI, George. Globalization. In: HELD, David; MCGREW, Anthony G. The Global Transformations Reader: an introduction to the globalization debate. $2^{\text {nd }}$ Ed., Cambridge: Polity, 2003. p. 55-59.

PINTO, Manoel de Jesus Souza. O Fetiche do Emprego: um estudo sobre as relações de trabalho de brasileiros na Guiana Francesa. 2008. 274 f. Tese (Doutorado em Desenvolvimento Sustentável do Trópico Úmido) - Núcleo de Altos Estudos Amazônicos, Belém, 2008.

SANTIAGO, Abinoan. Ponte entre AP e Guiana Francesa será aberta em janeiro, diz Dnit. G1 Amapá. Oiapoque, 04 dez. 2016. Disponível em:

<http://g1.globo.com/ap/amapa/noticia/2016/12/ponte-entre-ap-e-guianafrancesa-sera-aberta-em-janeiro-diz-dnit.html> Acesso em: 09 jan. 2017

SCHNEIDER, Sergio; SCHIMITT, Cláudia Job. O uso do método comparativo nas Ciências Sociais. Cadernos de Sociologia, Porto Alegre, v. 9, p. 49-87, 1998.

SILVA, Gutemberg de Vilhena; RÜCKERT, Arnaldo Aldomar. Território e poder no Planalto das Guianas. $7^{\mathbf{0}}$ Colóquio de Transformações Territoriais. Curitiba, 2008. Disponível em: <http://www.augm-cadr.org.ar/archivos/7mocoloquio/mesa_6/20080426.pdf> Acesso em: 07 jan. 2017 
77 InterAção

TEITELBAUM, Michael S. The Role of the State in International Migration. The Brown Journal of World Affairs. Providence, Volume VIII, Issue 2, p. 157-167, Winter, 2002. Disponível em: <https://www.brown.edu/initiatives/journalworld-affairs/sites/brown.edu.initiatives.journal-worldaffairs/files/private/articles/8.2_Teitelbaum.pdf> Acesso em: 13 jan. 2017

ÚLTIMA Fronteira do Brasil. SBT Repórter. Oiapoque, 29 jul. 2013. Disponível em:

$<$ https:/ / www.youtube.com/watch?v=IWudIX33Omw\&index=2\&list=PLlTw UeGEccuipLj6OhVwbQYM92vYPWZWB> Acesso em: 09 jan. 2017

UNITED NATIONS. Department of Economic and Social Affairs. Disponível em:

<http://www.un.org/en/development/desa/population/theme/internationa l-migration/> Acesso em: 15 jan. 2017 